Revista Iberoamericana, Vol. LXXVIII, Núm. 240, Julio-Septiembre 2012, 605-621

\title{
LA ALQUIMIA DE UN GÉNERO. SERGIO PITOL Y EL ENSAYO LITERARIO
}

\author{
POR \\ María del Pilar Vila \\ Universidad Nacional del Comahue
}

Todo escritor, para escribir con claridad, debe ponerse enel lugar de sus lectores, examinar su propia obra como algo nuevo para él, que lee por primera vez, en lo que no toma parte alguna, y que el autor habría sometido a su crítica; y luego, convencerse de que no sólo nos comprenden porque nos entendemos nosotros mismos, sino porque somos realmente inteligibles.

La Bruyère

En 1969, Arturo Uslar Pietri afirmaba que los géneros habían desaparecido y se preguntaba si alguien: “¿[...] podría con alguna pretensión de eficacia, distinguir en lo que se escribe en nuestros días la tragedia de la comedia, o la prosa de la poesía, o lo lírico de lo épico, o la novela del poema, o el ensayo de la literatura de ficción?” (93). Próximo al tratado, vecino de la crónica, lindante con el trabajo científico, con el artículo académico y hasta con la nota periodística, aún hoy el ensayo no puede desprenderse de la metáfora creada por Alfonso Reyes. Más allá de las distintas perspectivas con las que fue analizado, el centauro de la prosa siempre mantuvo como rasgo sustancial el carácter de texto reflexivo, sin abandonar la experimentación, la recuperación de conceptos preformados y la fragmentación. Esta celebrada y con frecuencia aludida definición encuentra cabida en los ensayos del escritor mexicano Sergio Pitol (1933), cuya vasta producción conforma un verdadero mapa de lecturas en el que la lectura y la escritura son ejes centrales para el análisis de sus trabajos. Desviaciones, replanteos y transformaciones de temas arman una constelación de textos que, confirmando el carácter "anti-dogmático" del ensayo (Starobinski 38), permiten reunir la crónica, el diario y la ficción en libros difícilmente clasificables desde el punto de vista genérico, en especial porque la relación de Pitol con la literatura siempre "ha sido visceral, excesiva y semisalvaje” (Arte 15). 
Los temas que el mexicano desarrolla en los ensayos circulan por la literatura, la teoría y la crítica literarias, sin dejar de lado aspectos relacionados con la sociología, la política y hasta la ciencia. Son textos que albergan los más diversos saberes e incorporan pasajes descriptivos, confesionales o narrativos, evidenciando una permeabilidad que complejiza su obra.

Sergio Pitol integra la generación del medio siglo mexicano, pertenencia que lo aproxima a una vida cultural marcada por los cambios y también por un cierto abandono de la temática revolucionaria. Varios críticos incluyen en la generación del medio siglo mexicano, además de Pitol, a Jorge Ibargüengoitia, Juan García Ponce, Inés Arredondo, Carlos Monsiváis, entre otros, y destacan el peso que tuvo para ellos "La revelación poética” de Octavio Paz. Quienes integran este grupo, entre otros aspectos, toman la noción de cambio y de la extrañeza como un eje relevante de sus obras: "Fue aquél un tiempo de innovaciones incesantes. La literatura, el cine, las artes plásticas, el montaje teatral cambiaban de lenguaje con una frecuencia inmoderada. Muchas de esas novedades me entusiasmaron, como a casi todos mis compañeros de generación”, aunque señala sus distanciamientos con ciertas posiciones radicales frente a la "renovación formal", rescatando que en su "caso el interés por lo nuevo jamás logró mitigar mi pasión por la trama” (Arte 174).

Dejan de lado, también, aspectos relacionados con cambios históricos para fortalecer sus reflexiones sobre la creación literaria, tema que es tratado con singular énfasis.

En gran medida, imbuido de los ideales que sostuvo ese grupo, Pitol despliega en su obra -y en particular en los ensayos- un intenso diálogo con las más diversas líneas literarias, pero será precisamente su alejamiento de los tópicos nacionales o revolucionarios el que marque su distanciamiento de algunos modelos narrativos, aunque sin alejarlo de su condición de escritor mexicano. Es por ello que acuerdo con las afirmaciones de Juan Antonio Masoliver Ródenas cuando dice que la narrativa de Pitol "es visceralmente mexicana" aunque su escritura no se centre en "la identidad nacional” ni en "la revolución mexicana" (63-64).

La posición crítica de Pitol ante la literatura de su tiempo queda explicitada cuando señala la molestia que le produce "la retórica hueca del discurso oficial, así como el conformismo de grandes sectores de la población ante la estrechez de nuestra vida democrática y el atraso del país” (Arte 160). Con fina ironía, además, alude a las diferencias con que debió enfrentarse para ser reconocido como escritor mexicano. En 1999, y mediado por el otorgamiento del Premio Literario Latinoamericano y del Caribe, Pitol afirmó que gracias a los premios consiguió el ingreso de su obra en el canon de la literatura mexicana y que el éxito logrado en Europa le permitió una creciente visibilidad

1 José Luis Martínez en El ensayo mexicano moderno II también incluye a García Ponce y Monsiváis, y señala que ambos son escritores singulares y dueños de una escritura apartada de las formas tradicionales, confirmando la consideración de este último aspecto como un dato relevante del grupo.

ISSN 2154-4794 (Electrónico)
ISSN 0034-9631 (Impreso) 
en su país ("Historia”). Sin embargo, los nombres centrales de la literatura nacional y de la ensayística no están desatendidos en el conjunto de su obra, tal como se observa en las referencias a Alfonso Reyes y Octavio Paz; ambos ocupan un lugar relevante puesto que de ellos toma el valor de la lectura como tema de análisis y discusión. Carlos Fuentes en "Radiografía de una década: 1953-1963" alude a los intereses de la cofradía -en la que incluye a Pitol- básicamente en lo referido a las lecturas que los unió y a la significación que tuvo Alfonso Reyes en la formación del grupo. ${ }^{2}$

La obra y el pensamiento de Reyes están presentes en especial cuando se refiere al modo en que éste transformó y renovó la lengua y, fundamentalmente, porque expresó su "pasión por el lenguaje” y porque, además, le debe al "gran polígrafo, y a los varios años de tenaz lectura, la pasión por el lenguaje” (Casa 145; Arte 170). Pitol da un paso más que su maestro al inscribir su propia obra en el interior del ensayo y, en un doble movimiento, el ensayo en su obra, tal como lo hace en algunas novelas. ${ }^{3}$

En los ensayos no sólo se observa su lectura de la tradición o cómo genera nuevos vínculos con otras literaturas, sino el lugar que el ensayista le da a la historia cultural latinoamericana y cómo la liga con la europea. Su idea de la literatura está vinculada con la elección de lecturas y autores universales, hecho que implica una clara apertura, una búsqueda de miembros para incorporar a "su tribu", aunque sin dejar de lado a aquellos que, desde América Latina y en especial desde México, postulan otra escritura, otra literatura y otros lectores, lo que produce una generosa mezcla y expansión de lecturas. En una breve pero profunda referencia a la particularidad de la escritura de Pitol, Reinaldo Laddaga lo define como “creador de cánones”, al tiempo que destaca la presencia de diversos autores cuyas obras se caracterizan por el "uso activo de formas extravagantes o caóticas"; esta enumeración le permite al mexicano unir nombres "que son paradigmas" con "un desfile de presencias diminutas" (Espectáculos 25-30). Esta operación es la que explica la relevancia que tienen las frecuentes alusiones a autores como Carlos Monsiváis, César Aira o el español Enrique Vila-Matas, junto con referencias a Borola, Reginito, Cristeta y Ruperto, "extravagantes personajes”, de historieta, gesto que evidencia cómo a Pitol le "agrada imaginar a un autor a quien ser demolido por la crítica no le amedrentara” (Arte 117).

Varios trabajos críticos han abordado la narrativa de Sergio Pitol centrando sus consideraciones en el carácter ficcional de toda la obra e incluyen en esta categoría a Pasión por la trama o El arte de la fuga o Adicción por los ingleses. ${ }^{4}$ Si bien la ficción

2 Como se observa, las figuras de Reyes y Paz fueron de gran importancia en la formación de quienes tratarán de leer oblicuamente la tradición. (Fuentes 56-92)

3 En especial en Domar a la divina garza, capítulo 1: 9-19.

4 En esta línea se encuentran los trabajos de Daniel Sada, Teresa García Díaz o Laura Cázares, por ejemplo. En cambio Juan Masoliver Ródenas atiende en forma particular la producción ensayística de Pitol a partir de la "especial concepción de los géneros" (63) con que trabaja el escritor mexicano, posición que comparto.

Revista Iberoamericana, Vol. LXXVIII, Núm. 240 Julio-Septiembre 2012, $605-621$
ISSN 0034-9631 (Impreso) 
está presente en algunos de estos libros, postulo leerlos como ensayos en la medida en que se observa que el autor trata cuestiones teóricas y críticas vinculadas con los géneros y aborda los distintos temas a partir de cruces fecundos con la tradición y el pasado, con la norma y la ruptura. Como afirma María M. Gigena, los distintos temas que aborda el mexicano, "son los ejes alrededor de los cuales se articula buena parte de su programa estético y los elementos constitutivos que vuelven una y otra vez como tematización, estructura o perspectiva desde la cual se organiza el material literario” (308).

El ensayista apela a lectores que puedan desprenderse de categorías genéricas y reconocer en ese singular entramado textual su proyecto creador. El lector, por su parte, se enfrenta con textos que, a partir de un modo particular de abordar la fusión y transfusión de géneros, lo impulsa a constituirse en copartícipe de ese proyecto. El autor reflexiona sobre cuestiones tales como la literatura o la música o la pintura y entrecruza referencias a su vida privada con diarios privados o con incrustaciones de obras de otros autores, destinando, incluso, un lugar para sus libros ficcionales. La táctica de estos textos consiste en mostrar un autor que interpela a la institución literaria, es decir, a los escritores, a los críticos y a los académicos, figuras con las que entabla un diálogo, y para hacerlo no abandona el lugar que ocupa como escritor. Cada uno de los temas tratados, provengan del dominio del que provengan, son resultado de la práctica lectora, actividad que es actualizada en el presente del ensayista y se desplaza a la escritura:

Leer significaba acompañar al señor Bloom por las tabernas de Dublín a principios de este siglo, a Fabricio del Dongo por la Italia posnapoleónica, a Héctor y Aquiles por las plazas de Troya y los campamentos militares que durante largos años la circundaron. Y escribir significaba. Y escribir significaba la posibilidad de embarcarse hacia una meta ignorada y lograr la fusión -debido a esa oscura e inescrutable alquimia de la que tanto se habla cuando se acerca uno al proceso de la creación- del mundo exterior y de aquel que subterráneamente nos habita. (Arte 164)

A la manera de un patchwork, entreteje diversas voces, restos de escrituras provenientes de los más disímiles escritos, y hasta resabios de textos conocidos y de otros no tanto. En estos ensayos no hay voces superpuestas en términos de predominio de unas sobre otras, ni se visualiza un orden jerárquico en esas alusiones, sino que las referencias mantienen su propio tono reorganizándose a través de una operación narrativa que impulsa la reflexión sobre la lectura y la escritura. Se está en presencia de un proyecto de escritura que escudriña y explora sin dar una visión totalizante de los tópicos abordados y que más bien se orienta a desplegar un ejercicio tendiente a la construcción de un texto conformado por una gran variedad de 'formas vecinas'. De allí que no coincido con quienes consideran ficcionales a libros como El viaje o el ya mencionado El arte de la fuga. Encapsular estas obras en la categoría novela, limitaría

Revista Iberoamericana, Vol. LXXVIII, Núm. 240 Julio-Septiembre 2012, 605-621
ISSN 0034-9631 (Impreso) 
la posibilidad de alcanzar la dimensión que propone el autor porque como acertadamente sostiene José Balza, los trabajos ensayísticos de Pitol constituyen una suerte de "heráldica de su propia obra” (31).

En efecto, cada uno de ellos, en especial los dedicados a escritores, se engarzan con su obra, dando cuenta de su proyecto creador en tanto son la matriz narrativa que sostiene toda su obra. O para decirlo en palabras de Pitol en entrevista con Carlos Monsiváis, en los ensayos se interpola "una que otra pequeña trama, un sueño, unos juegos y varios personajes" ("Entrevista”). Se trata, sin dudas, de una literatura que comparte fronteras con distintos discursos tomando de cada uno de ellos retazos, mínimos detalles e imperceptibles huellas para producir uno nuevo. Contribuyendo con esta operación de desplazar y hasta hacer entrar en crisis las más variadas teorías del género, Pitol recurre a préstamos que muestran la función social y política de los trabajos y que, además, generan un campo de debate donde se pone a la crítica en estado de crisis, aspecto que desde mi perspectiva constituye el rasgo más destacado del proyecto creador del mexicano.

Una vez más la pregunta acerca de cómo deslindar la obra de ficción de la ensayística se impone. Esta cuestión debe ser analizada a la luz de entender que sujeto y objeto ensayístico constituyen un único rostro de la meditación del escritor en la medida en que, de modo recurrente, Pitol reflexiona acerca de temas que son al mismo tiempo él, su vida privada, sus idas y venidas por la literatura y su idea de la ficción. La libertad compositiva que encuentra en esta "filigrana narrativa" es la que posibilita no congelar o reducir el ensayo clasificándolo o encerrándolo en una línea teórica y crítica (Gomís 41). Esto es así gracias a la natural rebeldía caracterizadora de este tipo de discurso, la que lo exime de quedar adherido de modo categórico a una u otra definición, exhibiendo de esta manera la condición de "más puro género impuro" (Aullón de Haro). Esta rebeldía se expresa en la producción ensayística de Sergio Pitol a través de los caminos zigzagueantes elegidos para discutir o revisar teorías, caminos que al mismo tiempo son dadores de ideas y de reflexiones. Son, además, el lugar del debate de las preocupaciones del ensayista por los temas de su tiempo y el ámbito en el que deja a la vista su permanente diálogo con distintos saberes sin abandonar las referencias a su propia obra.

Así como se podría preguntar cuál es el límite entre ensayo y ficción en El arte de la fuga o en Domar a la divina garza, o en qué momento un género invade a otro o por qué el autor trabaja sobre los límites genéricos, considero que El arte de la fuga o La casa de la tribu, por ejemplo, deben ser leídos al amparo de las particularidades del ensayo literario porque son siempre "un relato y la cápsula de una novela y una crónica de época y un trozo de autobiografía”. ${ }^{5}$ Frente a interrogaciones motivadas por la necesidad de

5 Así define Pitol la obra de la rusa Marina Tsvietáieva quien, además, enfrentó a los críticos de su tiempo con un trabajo “arrogante e inclemente pero [...] sustentado por verdades literarias” (Viaje 111).

\footnotetext{
Revista Iberoamericana, Vol. LXXVIII, Núm. 240 Julio-Septiembre 2012, 605-621 ISSN 0034-9631 (Impreso) ISSN 2154-4794 (Electrónico)
} 
anclar los textos en una única línea genérica, las afirmaciones de A. Fowler (1988) y de C. de Obaldía (1995) -quienes consideran al ensayo como "literatura en potencia" (de Obaldía 1) y sostienen que se puede hablar de un "modo ensayístico" (Folwer 115)-dan una respuesta iluminadora, aunque podría agregarse que la hibridez del género habilita al ensayista para citarse y repetirse en un juego de espejos, contribuyendo así a mostrar la labilidad del género. Sin dudas esa suerte de juego de cajas chinas que contienen cada uno de los libros de Pitol encuentra, en la reiteración de alusiones a su propia obra o a la de otros escritores, el dispositivo adecuado para desplegar su concepción de la literatura. ${ }^{6}$ Por otra parte, ese "modo ensayístico" nace del pacto de lectura que se genera con el lector, en particular cuando lo impulsa a desviarse de convenciones genéricas para reconocer el juego experimental del ensayo.

“Todo está en todas las cosas" es el título del capítulo que inicia El arte de la fuga y, además, es el principio fundamental de los alquimistas. A partir de esta premisa, con audacia, Pitol inicia otros caminos para escribir sobre la literatura, el cine, la pintura y sobre sí mismo. Con frecuencia remite a su concepción de la literatura y al modo en que construye su propio canon. En El mago de Viena, la expresión de la libertad con que piensa y entiende la literatura tiene una contundencia destacada:

\begin{abstract}
No pertenecía a ningún cenáculo, ni era miembro del comité de redacción de ninguna publicación. Por lo mismo no tenía que someterme al gusto de una tribu, ni a las modas del momento. [...] comencé a integrar libremente mi olimpo. Frecuenté a los centroeuropeos cuando, fuera de Kafka, no eran leídos aquí por nadie: a Musil, Canetti, Von Horvath, Broch, Ursidil, fascinado de conocer esa tradición [...] (90)
\end{abstract}

Este gesto constituye una marca significativa no sólo de su obra, sino de su posicionamiento en el campo cultural, especialmente en lo que respecta a visualizar cuál es la idea de literatura sobre la que opera y cómo esa idea remite a plantear su distanciamiento de muchos coetáneos. La certeza de escribir a contrapelo de modelos como el realismo mágico o de permanecer al margen de grupos le produce la idea de “escribir en el desierto" (Mago 226)

Por otra parte, la errancia del género lo lleva a encontrar puntos de contacto entre los más disímiles temas, evocar los grandes nombres de la literatura universal, fundir géneros $y$, a la manera borgeana, estructurar los ensayos con una notable proximidad con el relato breve. ${ }^{7}$ Desde esta posición se pueden leer sus trabajos, textos en los que se entrecruzan géneros, disciplinas, estéticas, pero en los que siempre el ensayo aparece

6 En un interesante artículo de Sergio Pitol, Cécile Quintana habla de las “autocitas y autoplagios” como particularidad sustantiva de la obra de Pitol (25-33).

7 Véase Alazraki, “Tres formas del ensayo contemporáneo”.

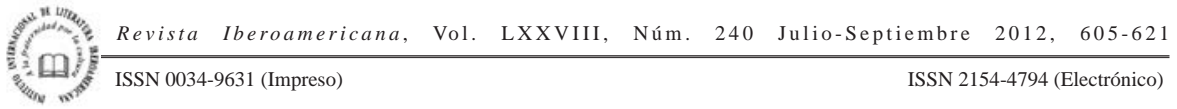


como “an essentially ambulatory and fragmentary prose form” (de Obaldía 2); los préstamos se insertan en el tejido textual, evidenciando que puede adoptar las formas más convenientes para cada circunstancia, sin descuidar la dimensión estética.

A partir de la reorganización y yuxtaposición de datos provenientes de la literatura, la historia o la política, de ficciones, de su diario privado, y en la que no están ausentes diálogos, crónicas y notas testimoniales y otras de un fuerte matiz periodístico, se van diluyendo los límites genéricos. El permanente descentramiento de tópicos marca el ensayar y la experimentación. Con esta estrategia consigue evitar el cierre de los temas y logra expresar, por ejemplo, las relaciones existentes entre cuestiones ideológicas, semánticas y de organización.

Pitol se mira escribir y observa el gesto de la escritura porque en ese acto está centrada la conciencia de ser escritor. Así va diseminando señales del movimiento interno que generan el proceso de la escritura al tiempo que delinea la travesía realizada para hablar de la literatura y del acto de creación. Pero sustancialmente, focaliza su atención en este último hecho como un modo de plantear su ars poética, sus deudas, sus alineamientos y sus distanciamientos. De modo que las referencias a determinados autores y el abandono de temas nacionales deben ser consideradas a la luz de ese propósito. Los caminos empleados para lograrlo expresan la validez que le otorga a los distintos datos de los que se sirve para presentar cada libro como una nueva y abierta propuesta.

Sin dudas su idea de la literatura, la construcción de su genealogía literaria y el papel del escritor están presentes de todos sus libros, y el modo de lograrlo es la elección de un género reflexivo que hace del ejercicio del pensamiento un modo de mirar el mundo y, al mismo tiempo, habilita al ensayista a mirarse a sí mismo. De allí que el valor de la experiencia alcance una dimensión muy alta. Como sostiene de Montaigne, "los hombres ensayamos todos los medios que a ello nos pueden llevar, y cuando la razón nos falta empleamos la experiencia” (231).

La experiencia está a la vista no sólo en la alusión a un "yo” que explica, relata, discute, sino también en la habitual remisión a acontecimientos de la vida privada, evocaciones de momentos juveniles íntimamente relacionados con la práctica de la lectura y de la escritura o a referencias que permiten establecer relaciones con otros textos y otras formas discursivas, armar "redes y familias textuales" y generar un vínculo simbólico entre un él y la sociedad, entre un él y el lector, entre un yo y un él y un nosotros (Weinberg, Situación 22).

Mi aprendizaje es el resultado de una lectura inmoderada de cuentos y novelas, de mis empeños como traductor y del estudio de algunos libros sobre aspectos de la novela escritos casi siempre por narradores, como el ya clásico de E. M. Forster, el elaboradísimo cuaderno de notas de Henry James, o el fragmentario de Anton Chéjov, así como de una larga serie de entrevistas, artículos y ensayos sobre novela también de novelistas; sin olvidar, por supuesto, las conversaciones de gente con oficio. (Pitol, Arte 171)

\footnotetext{
Revista Iberoamericana, Vol. LXXVIII, Núm. 240 Julio-Septiembre 2012, 605-621 ISSN 0034-9631 (Impreso) ISSN 2154-4794 (Electrónico)
} 
Como puede observarse, se incorporan datos del campo de la literatura, de la traducción y del periodismo, los que son reunidos de modo que ninguno de ellos tenga primacía sobre el otro. Se evidencia, además, la significación otorgada a la experiencia lectora la que funciona como fuente de legitimación y como explicitación de sus elecciones literarias. Esto produce un constante desplazamiento entre la práctica ensayística y la crítica académica y, para generar estos desvíos, el género es sumamente pródigo porque produce gran cantidad de efectos superficiales, oblicuas resonancias e “infinitos ensayos" que no quedan agotados sino que, antes bien, motivan la continuación del tratamiento de los temas presentados o abren camino para la discusión de ideas (Bensmaïa). En El viaje, Pitol afirma que “[a] veces es divertido provocarse. Claro, sin abusar; jamás me encarnizo en los reproches; alterno con cuidado la severidad con el ditirambo. En vez de ensañarme contra mis limitaciones he aprendido a contemplarlas con condescendencia y aun con cierta complicidad. De ese juego nace mi escritura” (9), evidenciando el modo en que pone en juego su idea de literatura. La articulación de estos campos, por otra parte, sirve de nexo para incorporar fragmentos contradictorios e incursionar en prácticas narrativas que pueden ser vistas como caóticas aunque en ese presunto desorden se encuentre el orden postulado.

Si bien todo ensayo se organiza de manera arbitraria, siempre hay una 'palabra suficiente' que le permite tener una función totalizante y encontrarle unidad (Bensmaïa 8). En tal sentido, es preciso atender a las estrategias textuales empleadas y a las historias, pensamientos y reflexiones que se van armando. En alguna medida, los ensayos del mexicano Pitol adquieren la fisonomía de un collage al relacionar diversos elementos y permitir al ensayista manipular objetos con independencia del sistema de origen. ${ }^{8} \mathrm{El}$ modo en que reúne estos campos permite identificar las distintas épocas en que emerge, básicamente a partir del reconocimiento de los datos, las ideas, las citas, los homenajes y los rechazos que alberga en su interior, como así también el reconocimiento de los itinerarios intelectuales y personales realizados por el autor. O dicho de otro modo, traza un mapa de la literatura latinoamericana de finales del siglo xx en el que se destacan complejos y renovadores autores.

Los continuos desplazamientos genéricos impulsan al lector a un permanente rearme de la lectura que, indefectiblemente, implica una revisión compulsiva de una inagotable biblioteca y una muestra precisa de cómo su experiencia personal deviene literatura. Así como el ensayista viaja a través de las lecturas (al igual que con los recorridos por las ciudades, la música o las pinturas), el lector implícito deberá desplazar su horizonte

8 Silvina Fazio postula, por ejemplo, considerar los discursos de aceptación de premios literarios como ensayos. Esta propuesta se funda en el hecho de que al alejarse de la instancia de agradecimientos, se leen como ensayos en los que se reflexiona acerca de cuestiones tales como "identidad latinoamericana", “literatura”, “generación” entre otras. En "Lo autobiográfico en los discursos de aceptación de premios literarios”. Inédito.

Revista Iberoamericana, Vol. LXXVIII, Núm. 240 Julio-Septiembre 2012, 605-621
ISSN 0034-9631 (Impreso) 
de lectura porque "la lectura es un juego secreto de aproximaciones y distancias" (Arte 229). Compartirlas implica trazar nuevos recorridos y revisar algunas figuras canónicas, tal como se observa en la siguiente afirmación:

\begin{abstract}
Yo adoro los excéntricos. Los he detectado desde la adolescencia y desde entonces son mis compañeros. Hay algunas literaturas en donde abundan: la inglesa, la irlandesa, la rusa, la polaca, también la hispanoamericana. En sus novelas todos los protagonistas son excéntricos como lo son sus autores. Laurence Sterne, [...] Jonathan Swift, Nicolai Gogol, [...] Virgilio Piñera, Thomas Bernhard, Augusto Monterroso, Flann O’Brien, Raymond Roussel, Marcel Schwob, Mario Bellatin, César Aira, Enrique Vila-Matas son excéntricos ejemplares, como todos y cada uno de los personajes que habitan sus libros, y por ende las historias son diferentes de las de los demás. (Mago 125)
\end{abstract}

La condición de excéntricos radica en la absoluta independencia con que se instalan en el campo cultural. Como Pitol, los elegidos trasgreden los géneros, dialogan con autores y leen su propia obra. El género guía la lectura con invisibles hilos hacia cuestiones a veces ocultas, otras a la vista, pero que señalan la presencia del autor y el propósito de abrir un debate de ideas, al tiempo que esas referencias funcionan como un montaje de saberes especializados. El ensayista se construye como una suerte de lector modelo en la medida en que puede descorrer velos con el fin de comentar, postular hipótesis, analizar y entrelazar ideas y preocupaciones. Sin agotar los temas, busca revisar, indagar y cuestionar voces de la tradición e integrarlas a partir de la relectura y de la información -aún indirecta o sesgada- al presente de la escritura, reuniendo la interpretación y la crítica. Uno podría preguntarse, junto con Ricardo Piglia, si esta operación, además de propiciar la lectura de textos que se fundan en la valoración de la extrema libertad genérica, no implica el propósito del autor por hacer visible la construcción de su identidad, y tal vez su tradición, a partir del modo en que se apropia de la extranjera. En rigor, su ligazón con distintas tradiciones está presente no sólo en sus ensayos de crítica literaria, sino que también se desarrollan en los textos ficcionales. El entrecruzamiento es tan notorio que por cierto contribuye a desdibujar los límites entre ensayo y ficción y a hacer visibles las obsesiones recurrentes de Pitol.

En "Viajar y escribir", por ejemplo, rememora el clima que vivía su generación frente a la posibilidad de escribir. A partir del reencuentro con "algunos fragmentos de un cuaderno autobiográfico escrito hace cosa de treinta años” (Arte 159), reflexiona acerca del significado de la iniciación en la vida literaria, de las relaciones con el mundo editorial y de sus vínculos con su país. El hecho privado, casi doméstico, es el disparador que lo impulsa a expresar, además, sus ideas acerca del modo en que los intelectuales se relacionaban con el poder. La historia menuda deviene reflexiones sobre la literatura y el camino que deben emprender los jóvenes escritores de su generación, camino que en el presente del ensayista se proyecta en la percepción que tiene de su país.

\footnotetext{
Revista Iberoamericana, Vol. LXXVIII, Núm. 240 Julio-Septiembre 2012, 605-621 ISSN 0034-9631 (Impreso) ISSN 2154-4794 (Electrónico)
} 
El encuentro con el texto escrito en el pasado genera un pregunta inquietante: “ ¿Por qué siento verdaderos escalofríos cada vez que pienso en regresar a mi país, lo que, como es natural, tendrá que ocurrir, quiéralo yo o no, algún día?” (Arte 159) En el contexto mexicano de entresiglos, esta pregunta es deudora de los caminos recorridos por Pitol, a veces al amparo y otras alejado de las figuras y las líneas finiseculares. ¿Cómo inscribir su ensayo en un ámbito en el que las voces de A. Reyes y O. Paz todavía dominan la escena? ¿Cómo explicar el deslizamiento de los ensayos centrados en cuestiones nacionales a otros focalizados en temas universales? Pitol explora no sólo la tradición latinoamericana, sino que incursiona en la europea y de modo especial en la rusa para encontrar allí las huellas de su propia producción literaria. Se puede afirmar, entonces, que el ensayista mexicano construye, según Alastair Fowler, "su canon personal” a partir de aquellas obras que "ha tenido ocasión de conocer y valorar" (97).

ENTRECRUZAMIENTOS DE VOCES

Soy una sombra de la sombra de alguien.

Marina Tsvietáieva

En ocasiones, Pitol hace referencias a circunstancias privadas -pero íntimamente relacionadas con la obras o con la escritura misma- de muchos de los autores a los que les dedica estudios. La singularidad de esos hechos (la vida de Dickens y sus avatares para sobrevivir en una sociedad cambiante; las dificultades de O’Brien para publicar su obra, por ejemplo $)^{9}$ son, en el presente del ensayista, acontecimientos públicos que han dejado de pertenecer a la intimidad del autor por la mediación de la relectura, hecho que sucede con su experiencia de lectura y de escritura para, una vez más, narrarse a sí mismo: "Debería revisar mis diarios de todo ese tiempo, como lo hago siempre antes de iniciar cualquier trabajo, para revivir la experiencia inicial, la huella primigenia, la reacción del instinto, el primer día de la creación” (Viaje 11). Las lecturas provienen de su condición de lector iniciático, y es en esa instancia cuando abandona la retórica de la crítica literaria para dar paso a un modo de relacionarse con la literatura desde lo anecdótico y desde lo contingente y particular. En este caso, uno de los episodios más significativos lo constituye "Iván, niño ruso" (Viaje 164), que se vincula íntimamente

9 En Adicción a los ingleses y en Pasión por la trama. Estos libros están estructurados sobre la base de una profunda reflexión acerca de la lectura, la escritura y los vínculos de sus autores con la literatura, abriéndose así un abanico de posibilidades de análisis en las que no están ausentes las filiaciones y afiliaciones. El contexto biográfico y sociocultural, a su vez, ocupa un lugar importante. El entretejido de ambos libros encierra el propósito del autor por develar nuevos modos de lectura, nuevos lazos entre escritores y, de modo sumamente productivo, se orienta a la revisión de la obra de escritores de la Europa oriental y de Latinoamérica.

Revista Iberoamericana, Vol. LXXVIII, Núm. $240 \quad$ Julio-Septiembre 2012,
ISSN 0034-9631 (Impreso) 
con sus contactos primeros con la lectura y con el mundo de la ficción. El otro camino elegido es el de su condición de lector crítico, momento en el que recurre a los comentarios o estudios de otros escritores como José Emilio Pacheco, Vicente Rojo o Juan Carlos Onetti y de teóricos como Mijail Bajtín y Víctor Sklovski. Al primero le reconoce su influencia en sus novelas escritas en Praga y en las lecturas de Chéjov y Gógol, en tanto que a Sklovski lo estudió “con constancia” (Viaje 20). Así como reúne géneros, fusiona su papel de crítico con el de escritor.

Pitol usa sus lecturas para exhibir su erudición, pero también su interés por expresiones artísticas alejadas del canon literario. El valor que le otorga a los trabajos del "fabuloso cartonista” Gabriel Vargas es un ejemplo significativo, dado que remite a la naturalidad con que Pitol enfrenta distintas perspectivas culturales; la lectura de la historieta La familia Burrón ${ }^{10}$ lo transformó en un “jubiloso lector durante varios años” (Arte 230), operación que está direccionada a mostrar cómo, al igual que Monsiváis, se desplaza de una cultura letrada a una cultura de masas.

El diálogo que entabla con escrituras provenientes de otros sistemas se traslada también a las que efectúa en el campo literario, como es el caso del trabajo dedicado a Flann O’Brien, inclusión que aparece mediada por la referencia a la lectura y al comentario que de la obra del irlandés hizo Jorge Luis Borges en El Hogar, de Buenos Aires (Pitol, Casa 116). En esta línea, aparecen también las referencias meticulosas a la obra del polaco Andrzej Kusniewic, a quien Pitol introduce de la mano de la referencia a la Teoría de la prosa de Víctor Sklovski (Casa 202). Junto con este soporte está su propia concepción de la escritura: "narrar una historia equivale a encontrar las notas con que formar una melodía. En el tejido de sus textos cada acorde es necesario para conquistar la totalidad" (Pitol, Casa 205). En este gesto, que se puede rastrear en la totalidad de su obra, se observa casi un juego de espejos: por un lado, inscribirse en una tradición más amplia, por otro, rendir su homenaje y reconocimiento, entre otros, al siempre presente Jorge Luis Borges. En el conjunto de la obra de Pitol hay una constelación de temas que, entre líneas, se amalgaman y se comunican constituyendo una única obra que renueva la idea fundante de que "todo está en todas las cosas”.

Por otra parte, el vínculo que establece con su lector se convierte en un diálogo profundo a partir del modo personal en que el autor entiende su relación y su situación en el mundo y su propia voz. Expresa su voluntad de relacionarse con su lector, para mostrarse como es porque, a la manera de Montaigne, es a él mismo a quien pinta.

${ }^{10}$ Gabriel Vargas García es el notable autor de esta historieta en la que se retrata la vida urbana mexicana. Pitol destaca el modo en que en esta historia popular los personajes tienen comportamientos comparables con "una finura exagerada, proustiana" o hablan "como palomas en arrullo de Vermeer". El capítulo "Borola contra el mundo" es una puesta en escena del modo en que en todo ensayo se produce un entrecruzamiento de lecturas sociales y culturales. Véase Arte 228-32.

\footnotetext{
Revista Iberoamericana, Vol. LXXVIII, Núm. 240 Julio-Septiembre 2012, 605-621 ISSN 0034-9631 (Impreso) ISSN 2154-4794 (Electrónico)
} 
Sinceridad, responsabilidad y compromiso constituyen ejes de la operación realizada por Pitol al momento de repensar su obra, depositando en las escenas de escritura no sólo la evocación de sus inicios como escritor, sino también el momento en que se hacen visibles sus reflexiones sobre la literatura.

Las frecuentes remisiones al ritual de la escritura se relacionan con los lugares de la escritura, sitios en los que se hacen presentes -o reaparecen- los autores elegidos para ese recorrido mental y físico por la literatura. El contacto con la ciudad lo conduce a revitalizar lecturas: "Hice un largo recorrido por las partes del viejo Leningrado. Advierto que no sé nada de la ciudad, o muy poco [...] se me ha vuelto una necesidad inaplazable releer Petersburg, de Andéi Béky, tal vez la novela más importante de este siglo" (Viaje 80). Se observa en este ejemplo una fuerte inscripción del yo, hecho que le posibilita rearmar su historia personal literaria, entretejer casi de modo constante las categorías de lectura y de escritura y trazar su propio mapa literario. De manera enfática deja a la vista su intervención en lo que escribe.

En ocasiones los textos discurren por instancias en las que la emoción es uno de los motivos relevantes para crear una atmósfera de profundas reflexiones. En otras prevalecen el juicio y la intuición, en especial la nacida al amparo de figuras tutelares aunque siempre con la idea de que hay que saber "saltar del tren en el momento preciso" (Mago 10), evidenciándose que el campo literario es especialmente pródigo para interpretar el mundo.

"El mono mimético" (Mago 9-13) es un ejemplo notable, no sólo como ejercicio de autorreferencialidad, sino también para observar la explícita presencia de Reyes:

lectura que lo reenvía a Stevenson y el concepto de “imitación” y la de Paz en el juego que realiza con el título. La enumeración minuciosa contiene aspectos que conducen a lograr “un lenguaje propio”, en tanto que la imitación es un gesto cargado de valor; para sostener la idea, recurre a Reyes y -mediado por éste- a Lope de Vega. Sin embargo, la advertencia es significativa: un escritor debe encontrar la ocasión adecuada para "desligarse de los lazos que lo ataban al estilo elegido como punto de partida e intuir el momento preciso de hacer suyo todo lo que requiere la escritura”. (Mago 10)

Las evocaciones de las lecturas realizadas en distintas etapas de su vida, en los viajes y en los largos paseos por las más diversas y distantes ciudades junto con los encuentros de amigos conforman los elementos cohesionantes de su escritura sin otorgarle a cada uno de ellos mayor espesura. ${ }^{11} \mathrm{El}$ mundo de los libros es el soporte más destacado de los

11 Las ciudades que emergen en varios de sus libros son un territorio retórico donde se reinscribe la relación de autor-literatura. Véase Vila, "La ciudad en los ensayos de Sergio Pitol”. Ponencia presentada en las XXX Jornadas Hispánicas y de América Latina "La ciudad y los imaginarios locales en las literaturas latinoamericanas”, Valparaíso, Chile, noviembre de 2007.

\footnotetext{
Revista Iberoamericana, Vol. LXXVIII, Núm. 240 Julio-Septiembre 2012, 605-621 ISSN 0034-9631 (Impreso) ISSN 2154-4794 (Electrónico)
} 
ensayos del mexicano. Las referencias a las críticas literarias e incluso a las traducciones conforman el sustrato y le permiten diagramar sus lecturas y su posicionamiento en el campo intelectual mexicano y cultural de América y Europa. ${ }^{12}$ Sin embargo, no deja de señalar que su proyecto se desvía de ciertas convenciones: "Me he resistido, desde siempre, a consumir los libros impuestos por la moda. Mi mapa de lecturas se ha ido trazando un poco al azar, por destino, temperamento y mucho de hedonismo. [...] Trato de vigilarme, de no inventarme gustos, de no cercarme” (Arte 228).

Sergio Pitol trabaja con la superposición de temas de modo casi paralelo al de la presentación de distintas estéticas y en esa trayectoria inquietante los desplazamientos hacia lecturas no tan reconocidas (y otras no tan conocidas) contribuyen a delinear su trabajo. Rastrea huellas, rearma caminos y, al bucear en voces ajenas, despliega su propia construcción de autor, explicitando los diversos aspectos que forman parte de su formación: “[e]l viaje como actividad continua, las frecuentes sorpresas, la coexistencia con lenguas, costumbres, imaginarios y mitologías diferentes, las diversas opciones de lectura, la ignorancia de las modas, la indiferencia ante las metrópolis, sus reclamos y presiones, los buenos y malos encuentros; todo eso afirmó mi visión” (Mago 43).

Leer y releer. No importa qué sino mostrar en ese gesto la valoración otorgada a esta actividad en tanto paso ineludible para la escritura, cuestión que, junto con la lectura, es el eje de toda su obra. Leer permite interpretar y, desde ese lugar, valorar aquellos aspectos que conforman la cultura y son portadores de significados y, contribuyen a la indagación, la experimentación y apelan a la actividad interpretativa. Es necesario destacar que la doble operación -lectura/escritura- responde a la ligazón existente entre un imaginario y un sistema simbólico "relacionados a su vez con el lenguaje y las instituciones” (Weinberg, Ensayo 495).

Los autores elegidos están inscriptos en el campo de la institución literatura y gozan, mayoritariamente de un alto reconocimiento, son los "padres de la literatura" o, al menos, en el decir de Juan José Saer, los “tíos narradores” (77). ${ }^{13}$ De modo que la lectura de textos reconocidos y emblemáticos constituye un proceso de simbolización en tanto “acontecimiento humano que se vuelve comunicable e inteligible”, lo que tiende un puente entre la experiencia individual y la experiencia social (Weinberg, Ensayo

${ }_{12}$ Pitol es un excelente traductor de Conrad, James y Gombrowicz, entre otros. También traduce al escritor ruso Boris Pilniak, uno de cuyos libros fue además prologado por él. Los aspectos resaltados en el prólogo, y que están estrechamente ligados con el conjunto de la producción del ruso, reenvían a cuestiones centrales para el proyecto creador de Pitol. Véase Pilniak 5-12. Por otra parte le otorga a la traducción una gran importancia porque, según afirma, "no conozco mejor enseñanza para estructurar una novela que la traducción”. Véase El mago de Viena 227.

${ }^{13}$ Al hablar de la filiación de Dostoievski, Juan José Saer reemplaza al padre muerto por los "tíos narradores": Gogol, Balzac, Cervantes, entre otros, guían al ruso hacia "un mundo más grande y más flexible”. (Trabajos 77).

\footnotetext{
Revista Iberoamericana, Vol. LXXVIII, Núm. 240 Julio-Septiembre 2012, 605-621 ISSN 0034-9631 (Impreso) ISSN 2154-4794 (Electrónico)
} 
494), operación que convierte la experiencia en sentido. La lectura que hace de obras de otros escritores le permite pensar la suya, o para decirlo en términos de Eduardo Grüner, se trata de "una lectura que actualiza la escritura, que constituye al sujeto de lectura en el mismo lugar en el que se constituye el sujeto de la escritura: el presente perpetuo (continuo, si se quiere gramaticalizar) de la enunciación" (15; énfasis en el original). Ese continuo enriquece la relación constante que entabla con la literatura, reconociendo que "los momentos más fecundos de la cultura son aquellos en los que, separándose de la fatalidad biológica o de una tradición demasiado rígida que a veces se pretende tan inexorable como esa fatalidad, esos grupos o individuos reivindican un filiación novedosa” (Saer 76).

En varias oportunidades Pitol recurre a otras referencias para dejar huellas autobiográficas y evocaciones muy intensas: rememora encuentros literarios o visitas a casa de escritores para, así, rearmar la atmósfera en la que se debatían cuestiones teóricas y críticas. Será ese ámbito y esos paseos los que le permiten establecer vínculos entre escritores latinoamericanos y europeos y, en el medio, revisar su propia colocación en el campo literario mexicano, gesto que nos pone frente a un sujeto que es, al mismo tiempo, objeto de su meditación. Es lo que Weinberg denomina el pasaje de la subjetividad a la sujetividad. Se pone en relación una existencia particular y una experiencia vista en el transcurrir porque el sujeto del discurso tiene una historia con la que debe contar para llegar a buen fin con su obra. Esa historia es, por otra parte y de modo simultáneo, experimentación de sus facultades naturales. Se traza, entonces, de un recorrido heurístico que lo conduce al descubrimiento de sí mismo y, al mismo tiempo, al del mundo. Es, en síntesis, la escritura de una experiencia (Glaudes) o, una vez más, la voz de Montaigne al pensarse como materia de sus libros.

Los ensayos responden a una búsqueda constante para dar lugar a las más variadas formas de este género, no sólo en lo referido a su organización interna sino, sobre todo, en lo que respecta al modo de enunciación. El ensayista asume su tradición occidental y latinoamericana desde la selección de lecturas literarias al tiempo que desplaza esa tradición también al campo de la teoría y la crítica literarias.

En la mayoría de sus trabajos ensayísticos Pitol incorpora anclajes temporales que le permite señalar momentos relevantes de la historia de la literatura y estrechamente ligada con ella, alusiones a la historia fáctica, a la política tanto de su país como la de los que visita. No están ausentes las referencias a la economía y, desde luego, a la cultura. Se confirma una vez más que todo ensayista es alguien que conoce sin ser necesariamente un especialista en lo que analiza. Se propone, pues, abordar, con una cierta minuciosidad, aquellos aspectos que aluden a una cultura en tanto son resultado de “ciertos procesos de simbolización” (Weinberg, Ensayo 493). En los ensayos que

Revista Iberoamericana, Vol. LXXVIII, Núm. 240 Julio-Septiembre 2012, 605-621
ISSN 0034-9631 (Impreso) 
componen Pasión por la trama, ${ }^{14}$ el recorrido del yo y del yo en el mundo está orientado a señalar los lazos que el ensayista teje con la tradición y con sus contemporáneos, armando así la historia intelectual en la que se inscribe. Está, además y sobre todo, el modo en que traducen simbólicamente su posición de intelectual y su relación con el mundo, con la res publica (Weinberg, Situación 53).

Los ensayos del mexicano se debaten entre la reflexión y la evocación, entre la conversación con el lector y el pensamiento solitario, entre el monólogo y el diálogo. En esa travesía, encuentra en el género una pródiga “cámara de ecos” dispuesta a albergar los más disímiles temas, al tiempo que teje redes 'familiares' proyectando especularmente un texto en otro texto.

Gabriel Zaid sostiene que el ensayo no se limita a ser un "informe de investigaciones realizadas en el laboratorio: es el laboratorio mismo, donde se ensaya la vida en un texto, donde se despliega la imaginación, creatividad, experimentación, sentido crítico del autor" (La carretilla s/n). Son precisamente estas expresiones críticas y creadoras, este constante ejercicio de experimentación y de imaginación los que están presentes en la obra ensayística de Sergio Pitol. Se trata de un corpus ensayístico que muestra cómo el autor hurga en el pasado para renovar el presente, movimiento que puede hacer porque la posición que ocupa en el campo cultural lo habilita para no sentirse atado o deudor de un grupo o de una generación, no obstante poner en evidencia sus elecciones, en especial las de sus coetáneos Monsiváis y Villoro. Con ellos rearma el álbum de familia, buscando afinidades por el tono y por relaciones nacidas de una idea común de literatura.

Como en una fuga musical, un sinfín de voces sostenidas “por la variación y el canon” (Mago 47) se disemina por la obra de Sergio Pitol en un ejercicio desafiante de lectura en el que no están ausentes las contradicciones en las que se debate el ensayista. Cada dato que incorpora denota la presencia de quien se detiene en esos detalles otorgándole, a veces, un valor casi insignificante y otras, dándole una complejidad manifiesta, pero siempre dirigido a señalar el modo en que interactúan entre ellos, interacción que nace de un estrecho vínculo entre escritura y lectura: "Escribir me parece un acto semejante al de tejer y destejer varios hilos narrativos arduamente trenzados donde nada se cierra y todo resulta conjetural; será el lector quien intente aclararlos, resolver el misterio planteado, optar por algunas opciones sugeridas: el sueño, el delirio, la vigilia. Lo demás, como siempre, son palabras” (Mago 48). Así, va dejando su sello el que se caracteriza por mostrar una literatura distinta y hasta irreverente pero que, de modo sesgado, va delineando la aventura intelectual del ensayista.

${ }^{14}$ La lectura del índice de este libro muestra el recorrido que efectúa por el campo cultural. A los nombres reiterados en varios ensayos, como el de Gogol, Chéjov, Nabokov, Tabucchi, Flann O’Brien o Monsiváis, se incorporan los de José Donoso, Álvaro Mutis, Walter Benjamin, los “dones y atributos” de Julio Verne y "Don Giovanni, ese dramma giocoso" de Mozart.

\footnotetext{
Revista Iberoamericana, Vol. LXXVIII, Núm. 240 Julio-Septiembre 2012, 605-621 ISSN 0034-9631 (Impreso) ISSN 2154-4794 (Electrónico)
} 
BiBLIOGRAFÍA

Alazraki, Jaime "Tres formas del ensayo contemporáneo". Revista Iberoamericana XLVIII/118-119 (enero-junio 1982): 9-20.

Aullón de Haro, Pedro. "Las categorizaciones estético-literarias de dimensión género/ sistema de géneros y géneros breves/géneros extensos”. AnMal Electrónica 15. Junio 2004. <http://www.anmal.uma.es/numero15/Aullon.htm>. 9 julio 2009.

Balza, José. "Páginas para Pitol”. Sergio Pitol: Los territorios del viajero. José Balsa, et al. México: Era, 2000. 31.

Bensmaïa, Reda. The Barthes Effect. The Essay as Reflective Text. Minneapolis: U of Minnesota P, 1987.

Cázares, Laura. El caldero faústico: la narrativa de Sergio Pitol. Iztapalapa: Universidad Autónoma Metropolitana, 2006.

Fazio, Silvina. "Lo autobiográfico en los discursos de aceptación de premios literarios”. Viedma: Universidad Nacional del Comahue, inédito.

Fowler, Alastair. “Género y canon literario”. Teoría de los géneros literarios. Miguel Ángel Garrido Gallardo, ed. Madrid: Arco Libros, 1988. 95-127.

Fuentes, Carlos. Tiempo mexicano. México: Cuadernos de Joaquín Mortiz, 1978.

García Díaz, Teresa. Victorio Ferri se hizo Mago en Viena. Sobre Sergio Pitol. México: Universidad Veracruzana, 2007.

"Vida y literatura: el continuo que une los mundos posibles, 'El mago de Viena' de Sergio Pitol”. Revista de Literatura Mexicana Contemporánea 29 (2006): 1021-1024.

Gigena, María M. "Viajar y escribir: El arte de la fuga de Sergio Pitol”. El despliegue. De pasados y de futuros en la literatura latinoamericana. Noé Jitrik, comp. Buenos Aires: NJ Editor, 2008. 305-10.

Glaudes, Pierre y Jean-François Louette. L'Essai. Paris: Hachette Livres, 1999.

Gómís, Anamari. "En homenaje a Sergio Pitol con motivo del Premio Juan Rulfo para Latinoamérica y el caribe”. Sergio Pitol: Los territorios del viajero. José Balsa, et al. México: Era, 2000.

Grüner, Eduardo. Un género culpable: La práctica del ensayo: entredichos, preferencias e intromisiones. Rosario: Homo Sapiens, 2000.

Laddaga, Reinaldo. Espectáculos de realidad. Ensayo sobre la narrativa latinoamericana de las últimas dos décadas. Rosario: Beatriz Viterbo, 2007.

Martínez, José Luis, ed. El ensayo mexicano moderno. Vol. 2. México: Fondo de Cultura Económica, 1995.

Masoliver Ródenas, Juan Antonio. “Sergio Pitol”. Fractal III/10 (julio-sept. 1998): 63-64.

Monsiváis, Carlos. "Entrevista a Sergio Pitol”. 8 oct. 2005. <http://www.ddooss.org/ articulos/entrevistas/Sergio_Pitol.htm>. 9 julio 2009.

Montaigne, Michel de. Ensayos. Buenos Aires: Orbis, 1984.

Revista Iberoamericana, Vol. LXXVIII, Núm. 240 Julio-Septiembre 2012, 605-621
ISSN 0034-9631 (Impreso) 
Obaldia, Claire de. The Essayistic Spirit. Literature, Modern Criticism and the Essay. Nueva York: Clarendon Press Oxford, 1995.

Paz, Octavio. "La revelación poética”. El arco y la lira. México: Fondo de Cultura Económica, 1956. 111-153.

Piglia, Ricardo. "Memoria y tradición”. Anais. $2^{\circ}$ Congresso ABRALIC: literatura e memória cultural. Belo Horizonte: Associação Brasileira de Literatura Comparada, 1991. 60-66.

Pilniak, Boris. Su majestad, Emperador. Santiago de Chile: LOM, 2002.

Pitol, Sergio. Adicción a los ingleses. Vida y obra de diez novelistas. México: Lectorum, 2002.

El arte de la fuga. Barcelona: Anagrama, 2005.

La casa de la tribu. México: FCE, 2006.

Domar a la divina garza. Barcelona: Anagrama, 1988.

“Historia de unos premios”. Letras Libres Febrero 2000. <http://www.letraslibres. com/index.php?art=6184>. 7 junio 2009.

El mago de Viena. Bogotá: FCE/Pre-textos, 2006.

Pasión por la trama. Madrid: Huerga \& Fierro, 1999.

El viaje. Barcelona: Anagrama, 2001.

Quintana, Cécile. "Los círculos escriturales”. Graffylia 5/7. Revista de la facultad de filosofía y letras (primavera 2007): 25-33.

Sada, Daniel. "La prosa conjetural de Sergio Pitol”. José Balza. Los territorios del viajero. México: ERA, 1999.

Saer, Juan José. Trabajos. Buenos Aires: Seix Barral, 2005.

Starobinski, Jean. “¿Es posible definir el ensayo?” Cuadernos Hispanoamericanos 575 (1998): 31-40.

Tsvietáieva, Marina. Mi Pushkin. Selma Ancira, trad. Barcelona: Acantilado, 2009.

Uslar Pietri, Arturo. En busca del nuevo mundo. México: Fondo de Cultura Económica, 1969.

Vila, María del Pilar. "La ciudad en los ensayos de Sergio Pitol”. Jornadas Hispánicas y de América Latina. Valparaíso, Chile. Noviembre 2007. Actas en CD.

Weinberg, Liliana. Situación del ensayo. México: UNAM, 2006. ed. Ensayo, simbolismo y campo cultural. México: Universidad Autónoma de México, 2003.

Zaid, Gabriel. "La carretilla alfonsina”. Letras Libres. Enero 1999. <http://www. letraslibres.com/index.php?art=5631>. 9 junio 2009.

\footnotetext{
Revista Iberoamericana, Vol. LXXVIII, Núm. 240 Julio-Septiembre 2012, 605-621 
